\title{
Impact of the Effort-Reward Imbalance Model on Intent to leave among Belgian health care workers: a prospective study.
}

\section{Abstract}

The aim of this study was to analyze the impact of the ERI model on intent to leave the current organisation (ITL organisation) and intent to leave the nursing profession (ITL profession) in a prospective way. A total of 1531 health care workers who remained in their job filled in a self-administered questionnaire at baseline and one year later. ERI was measured at baseline by a 23-item questionnaire. Multivariate logistic regression analyses were performed. Within a population with low intent to leave at baseline, we found that an imbalance between high efforts and low rewards (extrinsic hypothesis) increased the risk of high ITL organisation (OR 4.98; 95\% Cl 2.07-11.97) and high ITL profession (OR 1.84; 95\% $\mathrm{Cl}$ 1.03-3.30), one year later. A high level of overcommitment (intrinsic hypothesis) was not predictive for both intent to leave outcome variables, neither was the interaction between high efforts/low rewards and a high level of overcommitment (interaction hypothesis). Our results showed that an effort-reward imbalance is a significant predictor of intent to leave among health care workers. This contribution concludes with some directions aimed at boosting nurses' retention and recommendations for future research. 


\section{Introduction}

In the last decades, the demand for nurses has continued to increase due to a growing ageing population, an increased consumer behaviour in combination with higher patient expectations, and the rapid evolution of medical technologies (Coomber \& Barriball, 2007; Simoens, Villeneuve, and Hurst, 2005). At the same time, fewer young people are entering the nursing profession which may be the result of the low social value given to nursing and the negative perceptions of nurse working conditions (Kivimaki, Vahtera, Elovainio, Virtanen, and Siegrist, 2007; Simoens et al., 2005; Stordeur et al., 2003). Moreover, health care settings are facing high turnover of nursing staff and problems in recruiting new employees (Kivimaki et al., 2007; Stordeur et al., 2003; Stordeur \& D'Hoore, 2007). Organisational and professional turnover, like absence from work are, examples of work-related withdrawal behaviour (Krausz, Koslowsky, Shalom, and Elyakim, 1995). High turnover is a major problem for nursing and for health care in general. Beside substantial financial costs, turnover causes negative patient and nurse outcomes (e.g. increased waiting times, decreased patient and nurse satisfaction, adverse nurse health) (Aiken, Clarke, Sloane, Sochalski, and Silber, 2002; Hayes et al., 2006; Kivimaki et al., 2007; O'Brien-Pallas et al., 2006).

Understanding why health care workers abandon their current employer and/or their job in the nursing profession is essential, in order to retain them and to prevent turnover behaviour. One of the most important and strongest predictors of actual nurse turnover was found to be intention to leave (Borda \& Norman, 1997; Hayes et al., 2006; O'Brien-Pallas et al., 2006; Stordeur et al., 2007; Widerszal-Bazyl, Radkiewicz, Hasselhorn, Conway, and van der Heijden, 2008). According to Mobley (1977) revisited model actual turnover is the last stage of a decision-making process in which several turnover cognitions play a role, such as thinking of quitting, intent to quit and intent to search for a new job (Sager, Griffeth, and Hom, 1998). In health care, two turnover cognitions are of great importance: intent to leave the current health care organisation (ITL organisation) and intent to leave the nursing profession 
(ITL profession). This distinction between organisational and professional turnover intentions is been made, since organisational turnover is in particular the concern of the management of an individual health care setting, whereas professional turnover additionally has a societal impact, directly leading to a decrease of health care workers on the job market (Krausz et al., 1995).

Resigning and moving to another organisation or intending to do this can be interpreted as a way to actively or passively cope with an unhealthy work environment. Psychosocial work conditions have received growing attention as potential antecedents of turnover intention and actual turnover (Josephson, Lindberg, Voss, Alfredsson, and Vingard, 2008). Within this context several theoretical stress models have been developed to study the relation between job characteristics ('stressors') and stress reactions ('strains') (De Jonge, Le Blanc, and Schaufeli, 2007). Two prominent work stress models are the JDCS-model and the ERI model. The 'Job Demand-Control-Support' model (JDCS) introduced by Karasek (1979), (Karasek \& Theorell, 1990) postulates that the combination of high job demands, low decision latitude and low social support at work leads to reduced employee well-being and stress-related health complaints.

A second more recent stress model is the effort-reward imbalance model (ERI model) of Siegrist (1996). This model has its roots in medical sociology and emphasizes both the efforts and rewards at work (Marmot, Siegrist, Theorell, and Feeny, 1999). It has been suggested by Marmot et al. (1999) that the ERI model might have more power for explaining stress in the service occupations and professions, in particular those dealing with personbased interaction, such as health professionals. Another advantage of this model is the inclusion of both situational (extrinsic) and personal (intrinsic) characteristics (i.e. overcommitment).

The main assumption of the ERI model is that a failed reciprocity between high efforts spent at work and low occupational rewards received (effort-reward imbalance) may cause a state of emotional distress, which in turn can result in a sustained stress reaction and adverse effects on health and employee well-being (cf. labelled as the extrinsic hypothesis). 
It is assumed that people will not passively remain in a high effort-low reward situation, but instead will try cognitively and behaviourally to reduce their efforts and/or maximize their rewards (Van Vegchel, De Jonge, Bosma, and Schaufeli, 2005). This could be seen as a homeostatic regulation process (Vancouver, 2000). Functional homeostatic regulations at work involve self-regulation processes in order to cope with states of psychological imbalance at work induced by stressors at work (Pomaki \& Maes, 2002). Developing turnover intentions might be viewed as one way of coping with an effort-reward imbalance. In addition, recurrent reward frustration was found to reduce commitment and motivation of employees and to increase withdrawal behaviour (Godin \& Kittel, 2004).

Beside extrinsic work characteristics, a personal component is included in the model: overcommitment (OC). This intrinsic characteristic defines a set of attitudes, behaviours, and emotions reflecting excessive striving in combination with a strong desire to be approved and esteemed. Overcommitted employees exaggerate their efforts beyond levels usually considered appropriate (Siegrist et al., 2004; Van Vegchel et al., 2005). As a result, their susceptibility to reward frustration is increased (Siegrist et al., 2004). Employees experiencing a high level of overcommitment, possibly resulting in continued exaggerated efforts combined with disappointing rewards, are expected to have an increased risk of developing negative emotions which can cause possible adverse effects on health and employee well-being, even in the absence of an extrinsic effort-reward imbalance (Siegrist et al., 2004) (cf. labelled as the intrinsic hypothesis).

Overcommitment influences the perception of both effort and reward. Therefore overcommitted people are assumed to respond with more strain reactions to an effortreward imbalance, in comparison with their less overcommitted colleagues (Siegrist et al., 2004; Tsutsumi \& Kawakami, 2004) (cf. labelled as the interaction hypothesis).

In numerous studies the ERI model has been applied to a wide range of health outcomes in particular to cardiovascular disease outcomes (Kuper, Singh-Manoux, Siegrist, and Marmot, 2002) but it has been tested to a lesser extent in association with behavioural outcomes (e.g. 
sickness absence), and job-related well-being outcomes (e.g. work motivation, job satisfaction) (Van Vegchel et al., 2005).

To the authors' knowledge, in only two studies (Hasselhorn, Tackenberg, and Peter, 2004; Kinnunen, Feldt, and Makikangas, 2008) the ERI model was applied to the work-related outcome intent to leave. Both study designs (Hasselhorn et al., 2004; Kinnunen et al., 2008) however remained cross-sectional. As Van Vegchel et al. (2005) argued, there is still a high need for non-cross-sectional research designs.

Therefore, the aim of the present study is to investigate the effort-reward imbalance model by testing all three hypotheses in a prospective way, using the standardized ERI questionnaire developed by Siegrist et al. (2004) on two outcome variables: intent to leave the nursing profession (ITL profession) and intent to leave the current healthcare organisation (ITL organisation).

Study hypotheses:

Hypothesis 1: (Extrinsic hypothesis): An imbalance between high occupational efforts and low rewards increases the risk of developing a high ITL profession $(\mathrm{H} 1 \mathrm{a})$ and a high ITL organisation $(\mathrm{H} 1 \mathrm{~b})$ one year later.

Hypothesis 2: (Intrinsic hypothesis): A high level of overcommitment increases the risk of developing a high ITL profession $(\mathrm{H} 2 \mathrm{a})$ and a high ITL organisation $(\mathrm{H} 2 \mathrm{~b})$ one year later.

Hypothesis 3: (Interaction hypothesis): Nursing staff reporting an effort-reward imbalance in combination with a high level of overcommitment have an even higher risk of developing a high ITL profession $(\mathrm{H} 3 \mathrm{a})$ and a high ITL organisation $(\mathrm{H} 3 \mathrm{~b})$ one year later. 


\section{Method}

\section{Study sample}

The WOQUAL (health and safety for work quality) study is a research project further exploring the longitudinal data of the Belgian sample from the Nurses Early Exit Study (NEXT) (Hasselhorn, Tackenberg, and Muller, 2003). Belgian participating institutions at baseline were selected using a stratified sampling procedure to reflect the national distribution of nursing staff by (1) type of institution (hospital, nursing home, and homecare service), (2) geographical spread (the three Belgian regions: Brussels, Flanders and Wallonia) and (3) ownership (private versus public institutions). Out of forty-eight selected health care organisations, a total of thirty-nine institutions volunteered in this study.

A prospective questionnaire-based design was used for data collection. Two selfadministered questionnaires with a time lag of one year were distributed among all nursing staff (i.e. nursing aides, registered nurses and specialized registered nurses) employed in the thirty-nine health care settings.

At baseline, between autumn 2002 and spring 2003 (Time 1), a total of 4257 questionnaires was returned, with an overall response rate of $61.3 \%$. To examine if the ERI model was predictive for intent to leave one year later, only those nursing staff members who remained working in their job and organisation during that year, received the second questionnaire (i.e. non-leavers), regardless of their participation at baseline. One year after the baseline assessment 2857 participants completed the follow-up questionnaire. Here the response rate was $48,0 \%$. A coding system was used which made it possible to match the two questionnaires of each participant. Finally, a total of 1531 participants, completed both questionnaires and were included in the prospective analyses. 


\section{Measures}

\section{Baseline predictors}

Effort-Reward Imbalance model.

To measure the three components of the Effort-Reward Imbalance (ERI) model, a standardised questionnaire, developed by Siegrist et al. (2004) containing 23 Likert-scaled items was used.

\section{Effort}

Effort was assessed by six items, measuring demanding aspects of the work environment, e.g. work pressure, time pressure, responsibility, working overtime, increasing demands and physical load. Items were answered in two steps. In the first step participants had to indicate if an item content described a typical experience of their job. The answer categories were "yes" and "no". If they agreed, participants had to evaluate in the second step on a four point rating scale to what extent they usually felt distressed by this typical experience. The overall effort score was ranging from 6 to 30 . The higher the score, the higher the level of distress. The Cronbach's alpha for the effort was 0.72 .

\section{Reward}

Reward was measured by eleven items, covering different rewards: financial reward ( 1 item: salary), esteem reward (5 items; i.e. respect and support) and career opportunities (4 items, i.e. promotion opportunities) and job security ( 1 item). The rating and scoring procedure was the same as for to the effort scale. The overall reward score varied between 11 and 55 . The higher the score, the more rewards the job offers. Cronbach's alpha for the reward scale was 0.80 . 
Several formulations to operationalize the co-occurrence of efforts and rewards, such as the discrepancy (i.e. relative excess), the interactive (i.e. multiplicative interaction) and the proportional form (i.e ratio term) are discussed by Van Vegchel, De Jonge, and Landsbergis (2005). We applied the main recommended formulation of effort-reward imbalance, namely the ratio term (Siegrist \& Peter, 1996) ${ }^{1}$. The ratio was computed by placing the effort score in the nominator, and the reward score in the denominator. The reward score had to be multiplied by a correction factor ( 0.5454$)$ because of an unequal number of items in the nominator and denominator (6/11). A value close to zero indicates a favourable condition (relatively low effort, relatively high reward), whereas values beyond 1.0 indicate a critical condition of high costs (efforts) and low gain (rewards). The ratio can be either used as a continuous variable or can be transformed into a binary variable ( values $\leq 1 \mathrm{vs.}>1$ ). In our study sample, the prevalence of a ratio above 1 at baseline was $4.4 \%$. Due to this low prevalence, our formulation of ERI may diminish statistical power. As suggested by Niedhammer, Tek, Starke, and Siegrist (2004), based on the continuous variable, quartiles were defined in order to obtain dose-response associations between ERI and the outcome variables. Consistent with other researchers (Godin, Kittel, Coppieters, and Siegrist, 2005; Kuper et al., 2002) we used the upper quartile of the distribution of the ERI ratio in order to define the people at risk.

\section{Overcommitment}

The last component of the ERI model comprised 6 items. Overcommitment is a personal characteristic and refers to the inability to withdraw from work obligations and the strong need for esteem and approval. Each item consisted of 4 answer categories: (1) strongly disagree; (2) disagree; (3) agree and (4) strongly agree. The total score was varying between 6 and 24. The higher the score, the more likely a subject is to experience overcommitment. In line with effort-reward imbalance, people exposed to high levels of overcommitment were

\footnotetext{
${ }^{1}$ Data analyses based on the multiplicative interaction and the relative excess operationalization of effort and reward showed weaker and less interpretable results in comparison with the ratio term for both dependent variables in our study.
} 
defined by using the upper quartile of the distribution among the total study population. Cronbach's alpha for the overcommitment scale was 0.78 .

\section{Outcome measures}

\section{Intent to leave the profession}

Similar to Widerszal-Bazyl et al. (2008), ITL profession was measured by three items based on one general question: "How often do you think about " (1) further qualification outside nursing; (2) giving up nursing; (3) giving up nursing and starting a different kind of job. Each item had six answer categories, ranging from never to every day. The ITL profession variable was dichotomised. Participants indicating thinking about the content of at least one item several times a month or more, were considered having a high ITL profession. In contrast, considering leaving a couple of times a year could be seen as natural for most professionals (Hasselhorn et al., 2003). Cronbach's alpha for the 3-item scale was 0.74.

\section{Intent to leave the organisation}

ITL organisation was measured by one single question: "How often do you think about leaving the current institution." Five answer categories ranging from 'never' to 'every day' were used. A similar item was also used by Kinnunen et al. (2008). Thinking sometimes a month or more often about leaving the current institution was considered as a high ITL organisation.

\section{$\underline{\text { Confounders }}$}

Several baseline variables were included as potential confounding variables of the relationship between the ERI model and both intent to leave indicators at Time 2 . Based on the existing literature about intent to leave and data from the NEXT-study (Boumans, de Jong, and Vanderlinden, 2008; Hasselhorn et al., 2003; Widerszal-Bazyl et al., 2008), following confounders were included for analyses: age (continuous), gender, type of health 
care organisation, education level and family situation. Two extra variables were added: number of working hours (Flinkman, Laine, Leino-Kilpi, Hasselhorn, and Salantera, 2008; Kinnunen et al., 2008; Van Vegchel, De Jonge, Meijer, and Hamers, 2001) and work schedule (Flinkman et al., 2008; Hayes et al., 2006; Siegrist, 1996), given that a high number of the nursing staff members worked part-time (Stordeur et al., 2003) and because working an inflexible shift schedule brings unique stresses and demands (Flinkman et al., 2008; Willis, O'Connor, and Smith, 2008). No a priori hypotheses were formulated regarding these confounders.

\section{Statistical analyses}

To assess, in a longitudinal design, the impact of the ERI model measured at baseline, on both outcome variables, participants reporting either a high ITL organisation or a high ITL profession at baseline, were excluded from further analysis consistent with Hasselhorn et al. (2008).

In order to explore whether effort-reward imbalance (ERI), overcommitment (OC) and possible confounding variables, all measured at baseline, were associated with the two outcome variables at Time $2, \mathrm{Chi}^{2}$ tests were performed.

Multivariate logistic regression was used to test all three hypotheses of the ERI model on both intent to leave outcomes. To examine the extrinsic and the intrinsic hypotheses, the two components (ERI ratio and overcommitment measured at baseline) were introduced separately to assess their relative contribution to the estimation of both intent to leave indicators. For the interaction hypotheses, the two components together with the interaction term ERI X OC were entered in the model. In all prospective analyses, adjustments were made for all mentioned confounding variables, regardless of the result of their univariate associations with both outcomes. The underlying reason for this was to prevent that potentially important variables were rejected. All variables were entered in a single step. Analyses were performed using SPSS 15.0 software. 


\section{Results}

Descriptive analyses

A total of 1531 health care workers participated in this prospective study, who were employed in different kinds of settings: $684(44.7 \%)$ in hospitals, $92(6.0 \%)$ in nursing homes and $755(49.3 \%)$ in home care settings. The majority $(92.5 \%)$ of them were women $(n=1416)$ against only 115 men (7.5\%). The mean age of the participants was 38.4 years and ranged from 22 to 63 years. The job seniority ranged from 1 to 37 years with an average of 15.3 years. Almost three fourth $(74.6 \%)$ of the health care workers were more than 5 years employed in their organisation.

Registered nurses $(73.1 \%)$ represented the majority of nursing staff members, followed by specialized registered nurses (19.7\%) and nursing aids (7.2\%).

Half of the nursing staff study population was working between 19 and 38 hours a week, $41.2 \%$ worked full-time and only a minority worked less than 19 hours a week $(8.1 \%)$.

A summary of these characteristics is presented in Table 1.

Insert Table 1 about here

Univariate analyses

Table 2 gives an overview of the univariate associations.

At baseline the prevalence of high ITL profession and high ITL organisation was respectively, 20.5\% and $10.2 \%$ (Table 1) and at Time 2, 17.8\% for high ITL profession and $8.7 \%$ for high ITL organisation (Table 2). Prospective analyses were conducted on a study population of 1187 participants for ITL profession and on a study sample of 1368 participants for ITL organisation. Of the two ERI model components (ERI and overcommitment), only effortreward imbalance was significantly associated with both intent to leave outcome variables $(p<0.001)$. For overcommitment, only a significant association was found with ITL profession $(p=0.012)$. 
Of the possible confounding variables, "type of health care institution" was significantly associated with both intent to leave outcomes $(p<0.001)$. ITL profession at T2 was highest in hospitals $(16.7 \%)$, and health care workers from nursing homes had the highest ITL organisation one year later (13.9\%). "Gender" was respectively significantly and borderline significantly associated with ITL profession $(p=0.002)$ and ITL organisation $(p=0.051)$. For both outcome variables men had the highest intent to leave, respectively $21.8 \%$ and $10.3 \%$. Furthermore, ITL organisation was significantly associated with "family situation" $(p=0.010)$ and "education level" $(p=0.033)$. The highest ITL organization was found among single parents (12.5\%) and specialized registered nurses (9.2\%). ITL profession was significantly associated with "number of working hours a week" $(p<0.001)$. Nursing staff working full-time had the highest ITL profession one year later (16.1\%),.

Age and work schedule were not significantly associated with both intent to leave indicators.

Insert Table 2 about here

Multivariate analyses

As indicated before, logistic regression analyses were performed in order to test all three hypotheses of the ERI model on both outcome variables.

Effort-reward imbalance was found to be a significant predictor for both intent to leave outcomes, even after adjusting for age, gender, type of health care organisation, education level, family situation, number of working hours and work schedule. Results showed that participants experiencing an imbalance between efforts spent and rewards received at baseline (Q4) had a 1.84 times higher risk (OR 1.84; 95\% Cl 1.03-3.30) of having a high ITL profession one year later and a 5 fold higher chance (OR 4.98; 95\% $\mathrm{Cl} 2.07-11.97$ ) of having high ITL organisation one year later, compared to health care workers in the lowest quartile (Table 3). Overcommitment was not significantly predictive for both intent to leave indicators, neither was the interaction between effort-reward imbalance and a high level of overcommitment. 


\section{Discussion}

\section{ERI model}

In this paper, the validity of the ERI model for predicting intent to leave was analyzed among a Belgian sample of 1531 mainly female health care workers in different settings. Support has been found for the extrinsic hypothesis (Hypothesis 1) but no evidence was gathered nor for the intrinsic (Hypothesis 2) nor for the interaction hypothesis (Hypothesis 3). According to van Vegchel et al. (2005), the extrinsic hypothesis has been the most intensively studied, and for a majority of studies including job-related well-being outcome variables, support has been found for this hypothesis, even after extensive confounder adjustment.

Our results showed that a failed reciprocity between efforts and rewards was a significant predictor of both ITL profession ( $\mathrm{H} 1 \mathrm{a})$ and ITL organisation $(\mathrm{H} 1 \mathrm{~b})$ one year later. Our findings were in particular, in agreement with two other, though, cross-sectional studies testing effortreward imbalance in association with intent to leave (Hasselhorn et al., 2004; Kinnunen et al., 2008). In the study by Kinnunen et al. (2008) the ERI model was applied to organisational turnover intentions among 1301 Finnish managers. The study by Hasselhorn et al. (2004) was based on the total European baseline data of a large sample of 21229 health care workers.

In the present study the intrinsic hypothesis $(\mathrm{H} 2)$ was not confirmed. Highly overcommitted nursing staff members did not seem to have an elevated risk for experiencing a high intent to leave one year. This is in line with the cross-sectional results of the study by Kinnunen et al. (2008) who also did not found support for the intrinsic hypothesis. Hasselhorn et al. (2004) however, obtained support for the intrinsic hypothesis tested on ITL profession. Although, the association between overcommitment and intent to leave was weaker than between ERI and intent to leave.

Not finding support for the intrinsic hypothesis could possibly be ascribed to the fact that effort-reward imbalance and overcommitment may have different time lagged effects (Van 
Vegchel et al., 2005). Whereas effort-reward imbalance might have shorter-term effects, the effects of overcommitment on intent to leave might be postponed, as a cause of which no effects of overcommitment were measurable after one year follow-up. Another possible explanation could be attributed to the overcommitment component itself. Preckel, Meinel, Kudielka, Haug, and Fischer (2007) mentioned that it would be interesting to further clarify the 'overcommitment' construct since its scale items suggest certain conceptual ambiguity. Siegrist (2008) suggested to make a differentiation between two possible sources of overcommitment: informal pressure imposed on employees by their work environment and truly intrinsic motivation of employees. Another explanation might be that overcommitment is a less important characteristic in health care compared to other populations (Van Vegchel et al., 2001). Other personal characteristics might be more important, like commitment (Stordeur et al., 2007).

Compared to the other two hypotheses, the interaction hypothesis has been less examined in literature (12 out of 52 studies) and no consistent results have been obtained with regard to job-related well-being outcomes (Van Vegchel et al., 2005). In our study, no support was found for the interaction hypothesis $(\mathrm{H} 3)$. Overcommitment did not seem to modify (i.e; increase) the effect of effort-reward imbalance on intent to leave one year later. This result differed from the findings of the cross-sectional study by Kinnunen et al. (2008) in which moderate support for the interaction hypothesis of the ERI model was found. The lack of support for this hypothesis may be due to our proper study population. In our sample, only a small part of the participants (4.4\%) was experiencing an effort-reward imbalance (i.e. ERI ratio higher than 1.0) at baseline. This low prevalence of effort-reward imbalance in comparison with other European countries (Hasselhorn et al., 2004), could be explained by the many job alternatives on the labour market for health care workers due to the perceived nurses' shortage and a high employers' demand for health care workers. As stated by Siegrist et al. (2004) effort-reward imbalance is the highest when employees are confronted with a lack of job alternatives and job insecurity. In general this is not the case in Belgian health care at present. In addition, the mean level of overcommitment in our sample was also 
lower in comparison with other European countries with exception of the Netherlands (Hasselhorn et al., 2004). Since Belgium had more favourable results for both effort-reward imbalance and overcommitment, this may have weakened the moderating effect of overcommitment on effort-reward imbalance.

\section{Strengths}

As indicated before, studies about the ERI model investigating work-related well-being outcome variables (i.e. intent to leave) are rather scarce (Van Vegchel et al., 2005). Moreover, the majority of them were using proxy-measures and were based on a crosssectional design (Bakker, Killmer, Siegrist, and Schaufeli, 2000; Hasselhorn et al., 2004; Kinnunen et al., 2008).

Therefore a strength of our study is the use of a prospective design, to investigate the ERI model in relation to two turnover intention outcome variables, respectively ITL organisation and ITL profession.

Also the fact that all three hypotheses of the ERI model were formally tested in one single study is rather unique (Van Vegchel et al., 2005). By excluding participants with high intent to leave at baseline, an appropriate design was assured. Another methodological strength was the use of the standardized questionnaire, developed by Siegrist et al. (2004), to measure the components of the ERI model and the proper adjustment for confounding variables.

\section{Limitations}

A notable limitation of our study is that sample attrition may have affected our results. From the initial 4257 participants, only 1531 of them were involved in both Time 1 and Time 2 measurements. A comparison between respondents and non-respondents suggested a healthy worker effect. Those who did not return the second questionnaire, were those who suffered from more adverse working conditions at baseline (i.e. higher efforts and lower rewards). Consequently, our findings may be underestimated due to this sample bias. 
More detailed post-hoc subject attrition analyses (data not shown), based on (Goodman \& Blum, 1996) revealed that in our data set substantial attrition led to non-random sampling, which affected the means and variances of some of the variables, but not the underlying relationships among the variables. Therefore, because longitudinal data analyses were performed, we can be confident that subject attrition did not affect our results.

Another possible weakness is the use of self-reported measures for the predictor and both dependent variables (ITL profession and ITL institution), through which a common-method bias might have played a role. Although, Spector (2006) recently stated that these influences are not as high as could be expected. In addition, it has been suggested that the use of selfreport measures for both exposure and outcome variables is less problematic when there is a prospective design (Tennant, 2001; Theorell \& Hasselhorn, 2005) and it even may be regarded as an advantage, since in the phases of "leaving the institution" or "the profession", the (subjective) perception is essential.

Finally, longitudinal designs do not automatically prove causality (Zapf, Dormann, and Frese, 1996). Therefore, it would be interesting to investigate different types of causation. The relation between $\mathrm{ERI}$ and intent to leave could also be explained by reversed causal relations such that high turnover intentions at baseline elicit (the development of) an effort-reward imbalance one year later. Alternatively, even reciprocal (bi-directional) relations in which ERI and intent to leave mutually influence each other are plausible (Shimazu \& De Jonge, 2009). Unfortunately, in the present study, we were not able to study alternative assumptions concerning reciprocity and reversed causation, since effort-reward imbalance was only measured at baseline.

\section{Study implications}

Despite these limitations our results clearly support the predictive value of experiencing an effort-reward imbalance for turnover cognitions such as turnover intentions with regard to the profession and the current job one year later (cf. extrinsic ERI hypothesis). 
If organisations want to effectively manage turnover of health care workers, they need to understand how to influence the decision-making process whereby nursing staff think about quitting. Management interventions at early stages in this process could reduce such thoughts and stifle the momentum of quitting before an employee develops firm intention to search for a new job.

In terms of practical implications, our results suggest that improving the working conditions by increasing the rewarding aspects of work and/or decreasing efforts could be efficient for reducing turnover intentions, especially to counter ITL organisation and/ or ITL profession. However, other approaches may be preferable, depending on the type of health care organisation, gender and age. Men and women may attach more importance to different rewarding aspects or are less/more distressed by certain demanding aspects of work. Probably the same can be applied to younger versus older health care workers. Therefore, it may be desirable to investigate the separate effects of the different types of rewards and efforts on health care workers' turnover intentions and other well-being indicators. Another challenging research revenue is to explore whether the use of job specific operationalization of job demands and job resources (e.g. cognitive, emotional, and physical) as described by De Jonge \& Dormann (2003), provide additional support for the extrinsic hypothesis.

Further research could also focus on the boundary conditions (moderators such as labour market, economic climate) under which the ERI model predicts withdrawal behaviours (e.g. turnover), or could explore interrelations between turnover cognitions (e.g. thinking of quitting, intention to quit, intention to search) and actual organisational and professional turnover in health care and non-health care employees. 


\section{References}

Aiken, L. H., Clarke, S. P., Sloane, D. M., Sochalski, J., \& Silber, J. H. (2002). Hospital nurse staffing and patient mortality, nurse burnout, and job dissatisfaction. JamaJournal of the American Medical Association, 288, 1987-1993.

Bakker, A. B., Killmer, C. H., Siegrist, J., \& Schaufeli, W. B. (2000). Effort-reward imbalance and burnout among nurses. Journal of Advanced Nursing, 31, 884-891.

Borda, R. G. \& Norman, I. J. (1997). Factors influencing turnover and absence of nurses: a research review. International Journal of Nursing Studies, 34, 385-394.

Boumans, N. P. G., de Jong, A. H. J., \& Vanderlinden, L. (2008). Determinants of early retirement intentions among Belgian nurses. Journal of Advanced Nursing, 63, 64-74.

Coomber, B. \& Barriball, K. L. (2007). Impact of job satisfaction components on intent to leave and turnover for hospital-based nurses: A review of the research literature. International Journal of Nursing Studies, 44, 297-314.

De Jonge, J. \& Dormann, C. (2003). The DISC model: Demand induced strain compensation mechanism in job stress. In M.F.Dollard, A. H. Winefield, \& H. R. Winefield (Eds.), Occupational stress in the service professions (pp. 43-74). London: Taylor \& Francis.

De Jonge, J., Le Blanc, P. M., \& Schaufeli, W. (2007). Psychosociale werkstressmodellen. In W.Schaufeli \& A. B. Bakker (Eds.), De psychologie van arbeid en gezondheid. (pp. 25-49). Houten: Bohn Stafleu Van Loghum.

Flinkman, M., Laine, M., Leino-Kilpi, H., Hasselhorn, H. M., \& Salantera, S. (2008). Explaining young registered Finnish nurses' intention to leave the profession: A questionnaire survey. International Journal of Nursing Studies, 45, 727-739. 
Godin, I. \& Kittel, F. (2004). Differential economic stability and psychosocial stress at work: associations with psychosomatic complaints and absenteeism. Social Science \& Medicine, 58, 1543-1553.

Godin, I., Kittel, F., Coppieters, Y., \& Siegrist, J. (2005). A prospective study of cumulative job stress in relation to mental health. Bmc Public Health, 5.

Goodman, J. S. \& Blum, T. C. (1996). Assessing the non-random sampling effects of subject attrition in longitudinal research. Journal of Management, 22, 627-652.

Hasselhorn, H. M., Tackenberg, P., \& Muller, B. H. (2003). Working conditions and intent to leave the profession among nursing staff in Europe (Rep. No. 7). Stockholm: National Institute for Working Life.

Hasselhorn, H. M., Tackenberg, P., \& Peter, R. (2004). Effort-reward imbalance among nurses in stable countries and in countries in transition. International Journal of Occupational and Environmental Health, 10, 401-408.

Hasselhorn, H. M., Conway, P. M., Widerszal-Bazyl, M., Simon, M., Tackenberg, P., Schmidt, S. et al. (2008). Contribution of job strain to nurses' consideration of leaving the profession - results from the longitudinal European nurses' early exit study. Scandinavian Journal of Work Environment \& Health, 75-82.

Hayes, L. J., O'Brien-Pallas, L., Duffield, C., Shamian, J., Buchan, J., Hughes, F. et al. (2006). Nurse turnover: A literature review. International Journal of Nursing Studies, 43, 237263.

Josephson, M., Lindberg, P., Voss, M., Alfredsson, L., \& Vingard, E. (2008). The same factors influence job turnover and long spells of sick leavea 3-year follow-up of Swedish nurses. European Journal of Public Health, 18, 380-385. 
Karasek, R. A. (1979). Job demands, job decision latitude, and mental strain: implications for job-redesign. Administration Science Quarterly 24, 285-307.

Karasek, R. A. \& Theorell, T. (1990). Stress, productivity, and the reconstruction of working life. New York: Basic Books.

Kinnunen, U., Feldt, T., \& Makikangas, A. (2008). Testing the effort-reward imbalance model among Finnish managers: The role of perceived organizational support. Journal of Occupational Health Psychology, 13, 114-127.

Kivimaki, M., Vahtera, J., Elovainio, M., Virtanen, M., \& Siegrist, J. (2007). Effortreward imbalance, procedural injustice and relational injustice as psychosocial predictors of health: complementary or redundant models? Occupational and Environmental Medicine, 64, 659-665.

Krausz, M., Koslowsky, M., Shalom, N., \& Elyakim, N. (1995). Predictors of Intentions to Leave the Ward, the Hospital, and the Nursing Profession - A Longitudinal-Study. Journal of Organizational Behavior, 16, 277-288.

Kuper, H., Singh-Manoux, A., Siegrist, J., \& Marmot, M. (2002). When reciprocity fails: effort-reward imbalance in relation to coronary heart disease and health functioning within the Whitehall II study. Occupational and Environmental Medicine, 59, 777-784.

Marmot, M., Siegrist, J., Theorell, T., \& Feeny, A. (1999). Health and the psychosocial environment at work. In M. Marmot \& R. G. Wilkinson (Eds.), Social determinants of health (pp. 105-131). Oxford: Oxford University Press.

Mobley, W. H. (1977). Intermediate Linkages in Relationship Between Job Satisfaction and Employee Turnover. Journal of Applied Psychology, 62, 237-240. 
Niedhammer, I., Tek, M. L., Starke, D., \& Siegrist, J. (2004). Effort-reward imbalance model and self-reported health: cross-sectional and prospective findings from the GAZEL cohort. Social Science \& Medicine, 58, 1531-1541.

O'Brien-Pallas, L., Shamian, J., Buchan, J., Duffield, C., Hughes, F., \& Laschinger, H. K. S. (2006). The impact of Nurse Turnover on Patient, Nurse, and System Outcomes: A Pilot Study and Focus for a Multicenter International Policy. Policy, Politics, \& Nursing Practice 7, 169-178.

Pomaki, G. \& Maes, S. (2002). Predicting quality of work life: From work conditions to self-regulation. In E.Gullone \& R. A. Cummins (Eds.), The universality of subjective wellbeing indicators (pp. 151-173). Dordrecht, the Netherlands: Kluwer Academic.

Preckel, D., Meinel, M., Kudielka, B. M., Haug, H. J., \& Fischer, J. E. (2007). Effortreward-imbalance, overcommitment and self-reported health: Is it the interaction that matters? Journal of Occupational and Organizational Psychology, 80, 91-107.

Sager, E. K., Griffeth, R. W., \& Hom, P. W. (1998). A comparison of structural models representing turnover cognitions. Journal of Vocational Behavior, 53, 254-273.

Shimazu, A. \& De Jonge, J. (2009). Reciprocal relations between effort-reward imbalance at work and adverse health: A three-wave panel survey. Social Science \& Medicine, 68, 60-68.

Siegrist, J. (1996). Adverse health effects of high effort-low reward condtions at work. Journal of Occupational Health Psychology, 1, 27-43.

Siegrist, J. \& Peter, R. (1996). Measuring effort-reward imbalance at work: Guidelines. Düsseldorf: Heinrich Heine University. 
Siegrist, J., Starke, S., Chandola, T., Godin, I., Marmot, M., Niedhammer, I. et al. (2004). The measurement of effort-reward imbalance at work: European comparisons. Social Science \& Medicine, 58, 1483-1499.

Siegrist, J. (2008). Effort-reward imbalance and health in a globalized economy. Scandinavian Journal of Work Environment \& Health, 163-168.

Simoens, S., Villeneuve, M., \& Hurst, J. (2005). Tackling nurse shortages in OECD countries (Rep. No. 19). Paris: OECD Publications Services.

Spector, P. E. (2006). Method variance in organizational research - Truth or urban legend? Organizational Research Methods, 9, 221-232.

Stordeur, S. \& D'Hoore, W. (2007). Organizational configuration of hospitals succeeding in attracting and retaining nurses. Journal of Advanced Nursing, 57, 45-58.

Stordeur, S., Kiss, P., Verpraet, R., De Meester, M., Braeckman, L., \& D'Hoore, W. (2003). Intent to leave nursing in Belgium. In Hasselhorn H.M., Tackenberg, P. and Müller, B. (Eds.), Working conditions and intent to leave the profession among nursing staff in Europe (Rep. No. 7, pp 125-135). Stockholm, Sweden: National Institute of Working Life.

Tennant, C. (2001). Work-related stress and depressive disorders. Journal of Psychosomatic Research, 51, 697-704.

Theorell, T. \& Hasselhorn, H. M. (2005). On cross-sectional questionnaire studies of relationships between psychosocial conditions at work and health - are they reliable? International Archives of Occupational and Environmental Health, 78, 517-522.

Tsutsumi, A. \& Kawakami, N. (2004). A review of empirical studies on the model of effort-reward imbalance at work: reducing occupational stress by implementing a new theory. Social Science \& Medicine, 59, 2335-2359. 
Van Vegchel, N., De Jonge, J., Meijer, T., \& Hamers, J. P. H. (2001). Different effort constructs and effort-reward imbalance: effects on employee well-being in ancillary health care workers. Journal of Advanced Nursing, 34, 128-136.

Van Vegchel, N., De Jonge, J., Bosma, H., \& Schaufeli, W. (2005). Reviewing the effort-reward imbalance model: drawing up the balance of 45 empirical studies. Social Science \& Medicine, 60, 1117-1131.

Van Vegchel, N., De Jonge, J., \& Landsbergis, P. A. (2005). Occupational stress in (inter)action: the interplay between job demands and job resources. Journal of Organizational Behavior, 26, 535-560.

Vancouver, J. B. (2000). Self-regulation in organizational settings: A tale of two paradigms. In M.Broekaerts, P. R. Pintrich, \& M. Zeidner (Eds.), Handbook of self-regulation (pp. 303-341). San Diego, CA: Academic Press.

Widerszal-Bazyl, M., Radkiewicz, P., Hasselhorn, H. M., Conway, P. M., \& van der Heijden, B. (2008). The Demand-Control-Support model and intent to leave across six European countries: The role of employment opportunities. Work and Stress, 22, 166-184.

Willis, T. A., O'Connor, D. B., \& Smith, L. (2008). Investigating effort-reward imbalance and work-family conflict in relation to morningness-eveningness and shift work. Work and Stress, 22, 125-137.

Zapf, D., Dormann, C., \& Frese, M. (1996). Longitudinal studies in Organizational Stress Research: A review of Literature with Reference to Methodological Issues. Journal of Occupational Health Psychology 1, 145-169. 
Table 1

Socio-demographic characteristics and study variables at baseline $(n=1531)$

\begin{tabular}{|c|c|c|c|c|}
\hline Variables & $\mathrm{n}$ & $\%$ & Mean (SD) & Range \\
\hline Age & & & $38.41(8.82)$ & $22 \sim 63$ \\
\hline Seniority in nursing profession & & & $15.31(8.68)$ & $1 \sim 37$ \\
\hline \multicolumn{5}{|l|}{ Seniority in current organisation } \\
\hline$\leq 1$ year & 111 & 7.3 & & \\
\hline $1-5$ years & 276 & 18.1 & & \\
\hline$\geq 5$ years & 1139 & 74.6 & & \\
\hline \multicolumn{5}{|l|}{ Gender } \\
\hline Male & 115 & 7.5 & & \\
\hline Female & 1416 & 92.5 & & \\
\hline
\end{tabular}

Type of health care organisation

Hospitals

$684 \quad 44.7$

Nursing Home

$92 \quad 6.0$

Home Care

$755 \quad 49.3$

Type of health care training

Nursing Aid

$108 \quad 7.2$

Registered Nurse

$1089 \quad 73.1$

Specialized registered Nurse

$294 \quad 19.7$

Family situation

Alone

$139 \quad 9.2$

Only adult with children

$75 \quad 5.0$

With another adult

$357 \quad 23.7$

With other adult and children

$936 \quad 62.1$

Number of working hours a week

$<19$ hours

121

8.1 


\begin{tabular}{|c|c|c|c|c|}
\hline$\geq 19$ and $<38$ hours & 757 & 50.7 & & \\
\hline$\geq 38$ hours & 614 & 41.2 & & \\
\hline \multicolumn{5}{|l|}{ Work schedule } \\
\hline Day work regular hours & 372 & 24.5 & & \\
\hline Day work others & 268 & 17.7 & & \\
\hline Only night shift & 72 & 4.7 & & \\
\hline Shift work without night & 467 & 30.8 & & \\
\hline Shift work with night & 337 & 22.3 & & \\
\hline High ITL profession & 307 & 20.5 & & \\
\hline High ITL organisation & 154 & 10.2 & & \\
\hline ERI ${ }^{*}$ ratio & 1489 & & 0.54 & $0.20 \sim 2.13$ \\
\hline $\mathrm{ERI} \leq 1$ & 1424 & 95.6 & & \\
\hline$E R I>1$ & 65 & 4.4 & & \\
\hline Overcommitment & 1512 & & $13.86(3.17)$ & 6 24 \\
\hline
\end{tabular}

${ }^{\star} \mathrm{ERI}=$ Effort-reward imbalance 


\section{Table 2}

Overall prevalence of intent to leave (ITL) at time 2 (T2) ( $n=1531)$ and univariate associations between baseline measures and high intent to leave (ITL) at time 2 (T2), one year later

\begin{tabular}{|c|c|c|c|c|c|c|}
\hline & \multicolumn{3}{|c|}{ High ITL profession T2 } & \multicolumn{3}{|c|}{ High ITL organisation T2 } \\
\hline & $\mathrm{n}$ & $\%$ & & $\mathrm{n}$ & $\%$ & \\
\hline Overall prevalence & 269 & 17.8 & & 127 & 8.7 & \\
\hline Baseline variables & $\mathrm{n}$ & $\%$ & $X^{2}(P)$ & $\mathrm{n}$ & $\%$ & $X^{2}(P)$ \\
\hline Age groups & & & $1.80^{\mathrm{a}}(0.406)$ & & & $4.54^{\mathrm{a}}(0.103)$ \\
\hline$<30$ years & 26 & 11.3 & & 22 & 8.6 & \\
\hline$\geq 30$ and $<45$ years & 67 & 10.3 & & 39 & 5.4 & \\
\hline$\geq 45$ years & 39 & 13.3 & & 15 & 4.7 & \\
\hline Gender & & & $9.30(0.002)$ & & & $3.81(0.051)$ \\
\hline Male & 17 & 21.8 & & 10 & 10.3 & \\
\hline Female & 115 & 10.5 & & 66 & 5.5 & \\
\hline \multicolumn{7}{|l|}{ Type of health care } \\
\hline organisation & & & $24.29^{\mathrm{a}}(<0.001)$ & & & $22.42^{\mathrm{a}}(<0.001)$ \\
\hline Hospitals & 80 & 16.7 & & 46 & 8.0 & \\
\hline Nursing Home & 5 & 7.7 & & 10 & 13.9 & \\
\hline Home Care & 47 & 7.5 & & 20 & 3.1 & \\
\hline Type of health care training & & & $1.69^{\mathrm{a}}(0.430)$ & & & $6.83^{\mathrm{a}}(0.033)$ \\
\hline Nursing Aid & 10 & 14.5 & & 7 & 7.6 & \\
\hline Registered Nurse & 86 & 10.8 & & 46 & 5.0 & \\
\hline Specialized reg. Nurse & 26 & 13.4 & & 23 & 9.2 & \\
\hline Working hours a week & & & $19.56^{\mathrm{a}}(<0.001)$ & & & $4.71^{\mathrm{a}}(0.095)$ \\
\hline$<19$ hours & 11 & 12.4 & & 8 & 8.6 & \\
\hline$\geq 19$ and $<38$ hours & 44 & 7.4 & & 29 & 4.4 & \\
\hline$\geq 38$ hours & 74 & 16.1 & & 35 & 6.8 & \\
\hline Family situation & & & $4.43^{b}(0.219)$ & & & $11.41^{\mathrm{b}}(0.010)$ \\
\hline
\end{tabular}




\begin{tabular}{|c|c|c|c|c|c|c|}
\hline Alone & 16 & 17.4 & & 11 & 9.2 & \\
\hline Only adult with children & 5 & 10.7 & & 8 & 12.5 & \\
\hline With another adult & 30 & 14.5 & & 21 & 7.4 & \\
\hline With other adult and children & 73 & 10.5 & & 36 & 4.4 & \\
\hline Work schedule & & & $8.52^{\mathrm{C}}(0.074)$ & & & $6.84^{\mathrm{C}}(0.145)$ \\
\hline Day work regular hours & 28 & 9.2 & & 13 & 4.0 & \\
\hline Day work others & 19 & 8.5 & & 9 & 3.9 & \\
\hline Only night shift & 6 & 11.8 & & 3 & 4.9 & \\
\hline Shift work without night & 40 & 11.5 & & 28 & 7.1 & \\
\hline Shift work with night & 38 & 16.1 & & 22 & 7.9 & \\
\hline ERI quartiles* & & & $18.06^{\mathrm{b}}(<0.001)$ & & & $27.31^{b}(<0.001)$ \\
\hline Q1 & 24 & 7.6 & & 8 & 2.4 & \\
\hline Q2 & 27 & 8.9 & & 10 & 3.1 & \\
\hline Q3 & 34 & 11.8 & & 22 & 6.9 & \\
\hline Q4 & 43 & 18.5 & & 31 & 11.1 & \\
\hline OC quartiles ${ }^{* *}$ & & & $10.94^{\mathrm{b}}(0.012)$ & & & $3.52^{b}(0.318)$ \\
\hline Q1 & 29 & 10.9 & & 17 & 6 & \\
\hline Q2 & 22 & 6.8 & & 13 & 3.8 & \\
\hline Q3 & 39 & 14.4 & & 22 & 7.1 & \\
\hline Q4 & 41 & 13.7 & & 22 & 6.3 & \\
\hline
\end{tabular}

Numbers of degrees of freedom is 1 unless stated otherwise; ${ }^{a}$ numbers of degrees of freedom is $2 ;{ }^{b}$ numbers of degrees of freedom is $3 ;{ }^{\circ}$ numbers of degrees of freedom is 4

Significant results in bold

${ }^{*} \mathrm{ERI}=$ Effort-reward imbalance

** $\mathrm{OC}=$ Overcommitment 


\section{Table 3}

Multivariate associations between baseline measures and intent to leave (ITL) at time 2 (T2), one year later

\begin{tabular}{|c|c|c|c|c|c|c|}
\hline Effort-reward imb & & & & & & \\
\hline$(E R I)^{a}$ & ITL pr & fession T2 & & ITL or & anisation T2 & \\
\hline & OR & $95 \% \mathrm{Cl}$ & $p$ & OR & $95 \% \mathrm{Cl}$ & $p$ \\
\hline Q1 & 1 & & & 1 & & \\
\hline Q2 & 0.99 & $0.55-1.81$ & NS & 1.20 & $0.45-3.23$ & NS \\
\hline Q3 & 1.17 & $0.65-2.10$ & NS & 2.85 & $1.19-6.80$ & 0.018 \\
\hline Q4 & 1.84 & $1.03-3.30$ & 0.041 & 4.98 & $2.07-11.97$ & $<0.001$ \\
\hline Overcommitment & & & & & & \\
\hline Q1 & & & 1 & & & \\
\hline Q2 & 0.69 & $0.38-1.28$ & NS & 0.79 & $0.36-1.75$ & NS \\
\hline Q3 & 1.59 & $0.91-2.77$ & NS & 1.52 & $0.75-3.08$ & NS \\
\hline Q4 & 1.45 & $0.83-2.52$ & NS & 1.36 & $0.67-2.77$ & NS \\
\hline $\mathrm{ERI} X \mathrm{OC}^{\mathrm{a}}$ & & & & & & \\
\hline ERI ratio $X$ & & & & & & \\
\hline overcommitment & 0.94 & $0.74-1.20$ & NS & 0.71 & $0.49-1.01$ & NS \\
\hline
\end{tabular}

